\title{
Inverse analysis of pavement layer moduli based on data collected by buried accelerometers and geophones
}

Bahrani, Natasha; Levenberg, Eyal; Blanc, Juliette; Hornych, Pierre

Published in:

Accelerated Pavement Testing to Transport Infrastructure Innovation

Link to article, DOI:

10.1007/978-3-030-55236-7_61

Publication date:

2020

Document Version

Peer reviewed version

Link back to DTU Orbit

Citation (APA):

Bahrani, N., Levenberg, E., Blanc, J., \& Hornych, P. (2020). Inverse analysis of pavement layer moduli based on data collected by buried accelerometers and geophones. In A. Chabot, P. Hornych, J. Harvey, \& L. G. LoriaSalazar (Eds.), Accelerated Pavement Testing to Transport Infrastructure Innovation : Proceedings of 6th APT Conference (pp. 592-601). Springer. Lecture Notes in Civil Engineering Vol. 96 LNCE https://doi.org/10.1007/978-3-030-55236-7_61

\section{General rights}

Copyright and moral rights for the publications made accessible in the public portal are retained by the authors and/or other copyright owners and it is a condition of accessing publications that users recognise and abide by the legal requirements associated with these rights.

- Users may download and print one copy of any publication from the public portal for the purpose of private study or research.

- You may not further distribute the material or use it for any profit-making activity or commercial gain

- You may freely distribute the URL identifying the publication in the public portal 
See discussions, stats, and author profiles for this publication at: https://www.researchgate.net/publication/343872764

\section{Inverse Analysis of Pavement Layer Moduli Based on Data Collected by Buried Accelerometers and Geophones}

Chapter · January 2020

DOI: 10.1007/978-3-030-55236-7_61

CITATIONS

0

4 authors, including:

Natasha Bahrani Baloch

Université Gustave Eiffe

4 PUBLICATIONS 2 CITATIONS

SEE PROFILE

Pierre Hornych

Université Gustave Eiffe

142 PUBLICATIONS 1,135 CITATIONS

SEE PROFILE

Some of the authors of this publication are also working on these related projects:

SMARTI - Sustainable Multifunctional Automated Resilient Transport Infrastructures View project

Biorepavation View project
READS

71

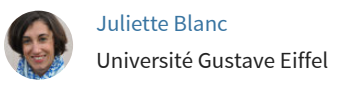

40 PUBLICATIONS 318 CITATIONS

SEE PROFILE 


\title{
Inverse analysis of pavement layer moduli based on data collected by buried accelerometers and geophones
}

\author{
Natasha Bahrani $^{1}$, Eyal Levenberg ${ }^{2}$ Juliette Blanc $^{1}$, Pierre Hornych ${ }^{1}$ \\ ${ }^{1}$ IFSTTAR, centre de Nantes, Route de Bouaye, 44341 Bouguenais CEDEX, France \\ ${ }^{2}$ Technical University of Denmark (DTU), Section for Geotechnics and Geology. \\ Corresponding author: natasha.bahrani@ifsttar.fr
}

\begin{abstract}
The aim of this study is to develop a method for identifying asphalt pavement layer properties based on readings from accelerometers and geophones that are embedded near the ride surface. These sensors are relatively small in size and easily embeddable, making them an ideal choice for wide-area applications in the live transportation network. As a first step, a section within the IFSTTAR accelerated pavement testing (APT) facility was instrumented with accelerometers and geophones; also installed was an anchored displacement sensor to serve as a reference/validation device. The APT facility offers the ability to control the loading configuration and intensity, travel speed, and wander (i.e., lateral offset) position relative to the sensor locations. Thus, it becomes possible to isolate the task of property identification through inverse analysis from other real-world complications. The paper commences by describing the experimental setup, and presenting some raw sensor measurements during a single pass of the APT's wheel carriage. Then, assuming a layered-elastic model, a method is proposed and demonstrated for estimating the pavement moduli. The method is based on best-matching measured velocities and accelerations for the geophones and accelerometers (respectively), with the model predictions- without integrating the signals to convert them into deflections. Very good match is obtained for the sensor readings, and the inferred moduli closely agree with reference values. This outcome means that there is great potential in building a pavement condition monitoring system with nearsurface accelerometers and geophones.
\end{abstract}

Keywords Pavement analysis, Sensor technology, Back calculation of pavement layer moduli. 


\section{Introduction}

Embedded sensing technologies are being developed and evaluated in recent years for wide-area instrumentation of pavement systems (Lajnef et al., 2013; Levenberg et al. 2014). In general terms, the aim is to carryout mechanical condition monitoring as well as usage monitoring. The current study investigates the application of near-surface single-axis geophones and accelerometers to determine pavement layer properties. The considered geophones and accelerometers measure, respectively, the vertical velocity and vertical acceleration of the pavement ride surface resulting from a passing vehicle.

A classical approach for interpreting the sensor measurements consists in integrating the signal traces with respect to time (once for the geophones and twice for the accelerometers), in order to arrive at deflections. Then after, the deflection basin can then be used in to analyse the pavement behaviour and back-calculate pavement layer properties (Clark et al., 1991; Liu et al., 2017; Arraigada et al. 2012; Ryynanen et al. 2012; Duong et al. 2018). This is typically done using methods similar to those applied for the Falling Weight Deflectometer (FWD) (Tholen et al. 1985; Nazarian et al. 1989). In the work of Duong (2018), geophone signals have also been used to identify vehicle types (number of axles) and travel speeds. An approach based on calculation of deflections from accelerometer and geophone signals is also included in Bahrani and al. (2020).

A different approach for interpreting the sensor measurements consists of matching directly the geophone or accelerometer measurements (or both) with the predictions of a pavement model (Levenberg, 2012; 2015). This approach completely avoids the need for integration, and is therefore well suited for noisy signals. An iterative or optimization procedure can be used to guide the matching and determine the sought layer properties. In the current paper the method is applied to analyze both geophone and accelerometer measurements made on the IFSTTAR accelerated pavement test (APT) facility as a means of back-calculating the elastic moduli of the pavement layers. The quality of the results is checked against measurements made with an anchored displacement sensor, and also with backcalculated layer moduli from FWD measurements.

\section{Experimental setup}

Three types of sensors were used for the tests: one single-axis geophone, and two single-axis accelerometers. An anchored deflectometer (displacement transducer) was also installed in the pavement, to serve as reference, because it measures the displacements with a high accuracy; however this type of sensor is less appropriate for measurements on live road network, due to its high cost and difficult installation. The characteristics of the geophone and accelerometers are presented on 
Figure 1. They were installed in an experimental pavement tested on the IFSTTAR Fatigue Carrousel, a circular outdoor Accelerated Pavement Testing facility (APT). The carrousel consists of a circular test track, of $40 \mathrm{~m}$ diameter, and a central loading system. A picture of the facility is shown in Figure 2. The test track is generally split into several sectors, each accommodating a different pavement structure. There are four identical loading arms at right angles, each housing a wheel carriage at the end. These wheel carriages can accommodate different tire arrangements, different load levels (up to $130 \mathrm{kN}$ per arm) and different lateral wander positions. The mean travel radius of the loading carriage is $19 \mathrm{~m}$, i.e. a circumference of about $120 \mathrm{~m}$. The width of the test pavement is between 3 and 6 meters. The maximum loading speed is $100 \mathrm{~km} / \mathrm{h}$, and the typical loading rate is 500000 carriage passes per month.

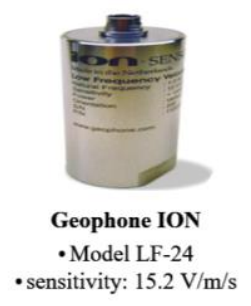

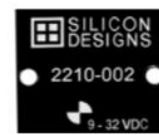

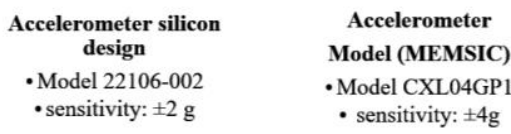

Fig. 1 Geophones and Accelerometers selected for the study

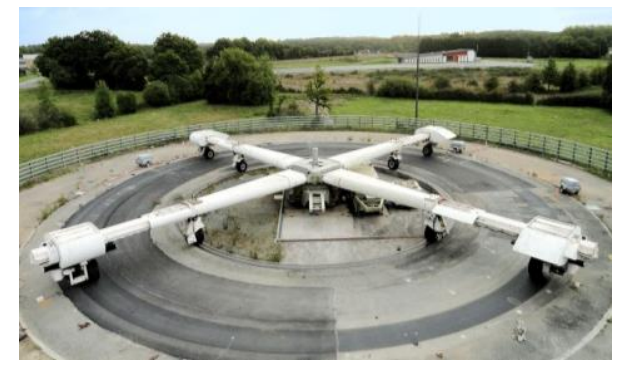

Fig. 2 View of the IFSTTAR APT facility

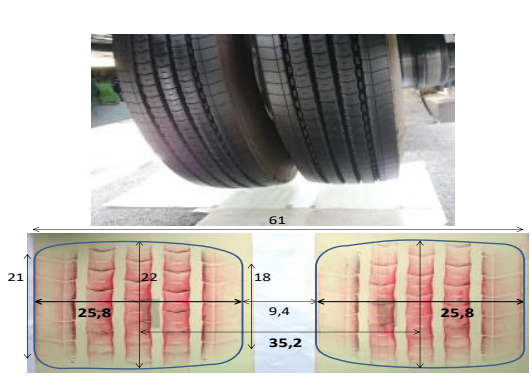

Fig. 3 Wheel Load dimensions

The pavement section investigated herein was a $22 \mathrm{~m}$ long sector; the structure consisted of two asphalt concrete (AC) layers, with a total thickness of $11 \mathrm{~cm}$ and a $30 \mathrm{~cm}$ thick $0 / 20 \mathrm{~mm}$ granular subbase, overlaying a clayey-sandy soil subgrade extending to a depth of $3 \mathrm{~m}$ and resting on a $20 \mathrm{~cm}$ concrete slab which is supposedly fixed. The structure was built in September 2017. Laboratory complex modulus tests have been performed on the $\mathrm{AC}$, characterizing the material across different temperature and frequencies (e.g., the norm of the complex modulus at $15{ }^{\circ} \mathrm{C}$ and $10 \mathrm{~Hz}$ was $11543 \mathrm{MPa}$ ). FWD tests and Benkelman beam measurements have 
also been performed, giving an average elastic modulus of $110 \mathrm{MPa}$ for the subgrade, and $145 \mathrm{MPa}$ for the granular layer.

The applied loads consisted of dual tires, with a contact surface of approximately $258 \mathrm{~mm} \times 220 \mathrm{~mm}$ (for each tire) and center-to-center spacing of $352 \mathrm{~mm}$ (see Figure 3). Tests were conducted under different load levels, between $45 \mathrm{KN}$ and $65 \mathrm{KN}$, different loading speeds, between $1 \mathrm{rpm}$ and $12 \mathrm{rpm}$ (i.e. between 7 $\mathrm{km} / \mathrm{h}$ and $87 \mathrm{~km} / \mathrm{h}$ ) and for 11 different lateral wheel positions.

\subsection{Instrumentation}

The section was instrumented in 2018 with the geophone and accelerometers, and also with an anchored vertical displacement sensor (based on LVDT S-series displacement sensor). The geophone and accelerometers were installed on the centerline of the pavement, one centimeter below the surface. They were glued with resin inside blind-holes drilled into the upper AC lift. They were oriented to measure vertical responses in the $\mathrm{z}$ direction with positive values in the downward direction. The effective measurement depth is from the mid height of the sensors to the top of the concrete slab (3 $\mathrm{m}$ deep). The geophone was ION LF-24, which uses the principle of a spring-mounted magnetic mass moving within a wire coil. The accelerometers were Silicon Design 22106-002 and MEMSIC CXL04GP1, which use MEMS capacitive technology.

\section{Data Analysis methodology}

\subsection{Pavement response calculation methodology}

The analysis of the deflection sensor, geophone and accelerometer measurements is based on the use of the multilayer linear elastic pavement calculation software ELLEA1(ver0.96), developed by Levenberg (2009)1. The approach consists of using the software to calculate the vertical displacement, vertical velocity and vertical acceleration at the position of each sensor, and matching the model predictions with the sensor measurements. For that purpose, an iterative procedure is used to adjust the model parameters (the pavement layer moduli), until the best match between the modelling results and the measurements is obtained. The final set of moduli corresponds to the estimated moduli of the pavement layers. This modelling methodology is successively applied to the deflection sensor, the geophone

\footnotetext{
${ }^{1}$ https://orbit.dtu.dk/files/125076641/ELLEA1_ver0.96_.xlsb
} 
and the two accelerometers, and the pavement layer moduli obtained with each sensor will be compared.

\subsection{Optimization of layer moduli}

For the pavement modelling, the initial characteristics considered for the pavement layers (elastic modulus and thickness of each layer) are those given in part 2 except for AC modulus which was adjusted according to the real test temperature and frequency. The wheel loading is $65 \mathrm{kN}$ and the dual wheel load distribution described in Fig. 3 is replicated for the simulation assuming circular contact areas. The Poisson ratio for all layers was set to 0.35 , and the tire-pavement contact stress to $0.6 \mathrm{MPa}$. The vertical displacements are calculated over a horizontal distance of approximately $5 \mathrm{~m}$ from the center of the load.

The optimization method, to determine the pavement layer moduli, is similar for all the sensors, and is based on the following steps:

1) Computing the pavement response (vertical displacement) with the modelling software for a passing wheel;

2) Calculating vertical velocities and accelerations by numerical derivation (finite difference formulas);

3) Comparing the computed response traces to the measured traces;

4) Finding the best match between the two response by adjusting the modulus parameters of the pavement;

The procedure allows obtaining a "best estimate" of the pavement layer moduli. Only the modulus values of the pavement model are adjusted in the optimization process, the other parameters are fixed.

\section{Comparison of measurements and model prediction and estimation of pavement layer moduli}

The optimization procedure described above was applied to the measurements made in the APT experiment using the different sensors, for different loading conditions (different load levels, loading speeds and load positions). The data presented in this paper correspond only to measurements made at an average temperature of $18^{\circ} \mathrm{C}$ in the AC layers, and speeds of $16 \mathrm{~m} / \mathrm{s}$ and $20 \mathrm{~m} / \mathrm{s}$ (corresponding to $\mathrm{AC}$ layer moduli of $9038 \mathrm{MPa}$ at $16 \mathrm{~m} / \mathrm{s}$ and $9441 \mathrm{MPa}$ at $20 \mathrm{~m} / \mathrm{s})$. The sensors were placed in the center of the wheel path, between the dual wheels represented in Figure 3. For each load condition, measurements were made during several successive load applications, but for the modelling, only a single wheel load signal 
was considered. The duration of the signal was about $1 \mathrm{~s}$ to $1.5 \mathrm{~s}$, corresponding to about 500 to 600 recorded measurement points.

A global error indicator is defined, $\mathrm{R}$, characterizing the relative difference (in percent) between the model response and the reference values (measured sensor response). This indicator calculates the pointwise difference between the two signals, divided by the absolute maximum value of the measured response as defined in Eq. 1, where $\mathrm{N}$ is the total number of reference points.

$R=\frac{1}{N} \sum \frac{\text { Reference value }- \text { Calculated value }}{\text { Max }(\text { Reference value })} \times 100$

This difference $\mathrm{R}$ is then minimized by optimizing the modulus values of the model to obtain the best match of the calculated and measured values. The minimization is carried out using Solver which is the gradient optimizer in Excel (Fylstra, 1998). In the solver, maximum and minimum attainable modulus values are fixed for each layer, as represented in Table 2, to avoid getting unrealistic solutions. The choice for these bounds can be considered inconsequential, as long as they encapsulate the optimal solution.

Table 2 Limits for the optimization of the back calculation

\begin{tabular}{lcc}
\hline Pavement Layer & Min Modulus (MPa) & Max Modulus (MPa) \\
\hline Bituminous layer & 8000 & 12000 \\
Granular base & 100 & 200 \\
Subgrade & 50 & 150 \\
\hline
\end{tabular}

The different signals selected for the comparison with the ELLEA1 model predictions are presented in Figure 5. Each graph represent the response measured by one sensor (displacement sensor, geophone or accelerometer), under the passage of a moving wheel at $16 \mathrm{~m} / \mathrm{s}$ or $20 \mathrm{~m} / \mathrm{s}$, and the corresponding predicted values, before and after optimization. Positive values represent downwards displacements, velocities and accelerations.

The displacement signals indicate a positive deflection when the wheel is approaching, and then a return to zero when the wheel drives away. The measured displacement signal is not completely symmetrical, most probably due to the viscoelastic behaviour of the AC layers (the return to zero is slower). The vertical velocity signals are positive when the wheel approaches, and then negative. The vertical acceleration signal is first positive, when the wheel is approaching, then negative under the wheel, and then positive again when wheel drives away. The acceleration signals are also slightly asymmetrical, and present more noise than the other signals, due to the low acceleration levels.

As can be seen in Figure 5 for all sensors, the modelling results are in good agreement with the measurements, except that the calculated signals are symmet- 
rical, due to the elastic model used. After optimization, the match with the measurement is only slightly improved.

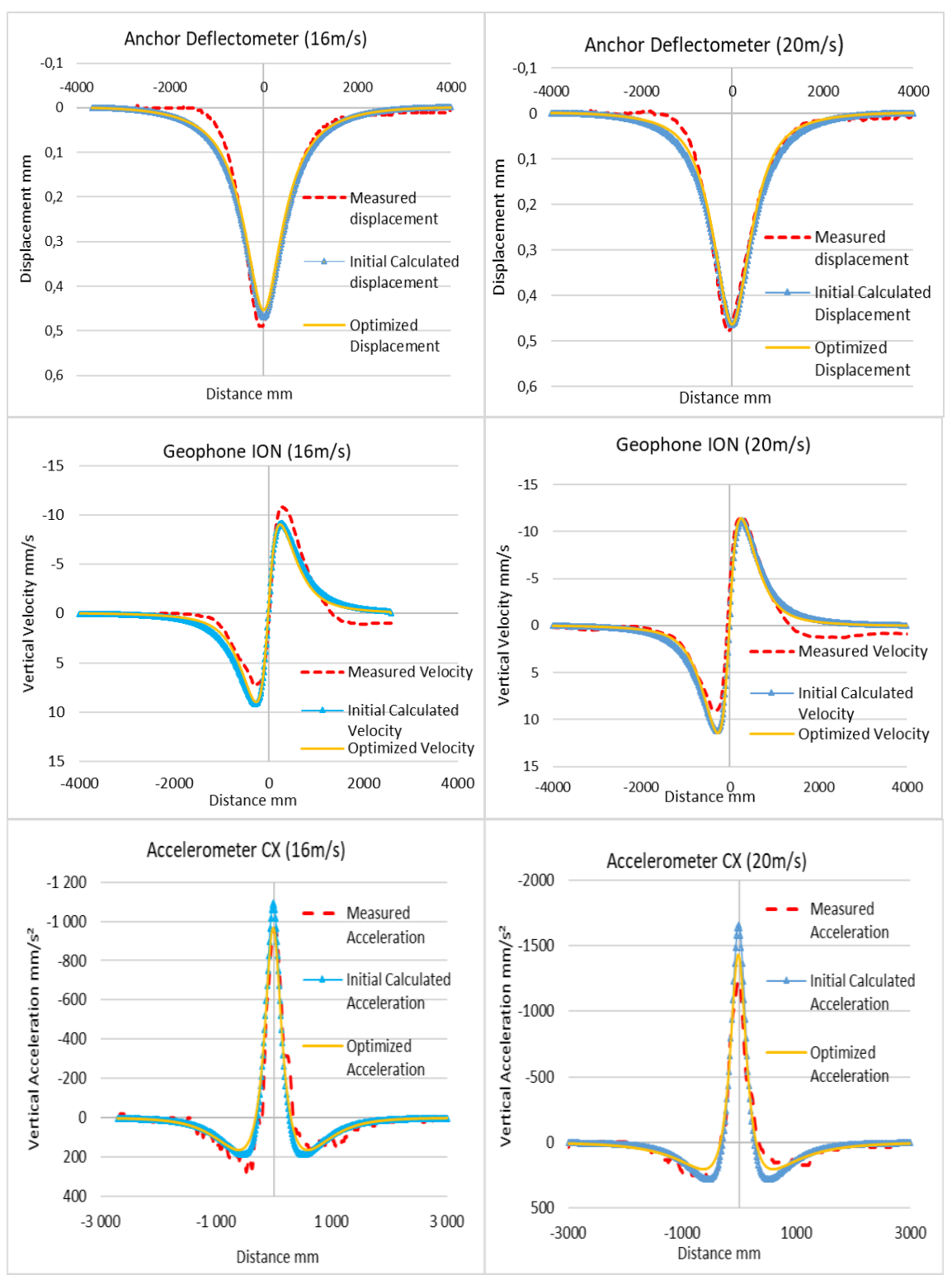




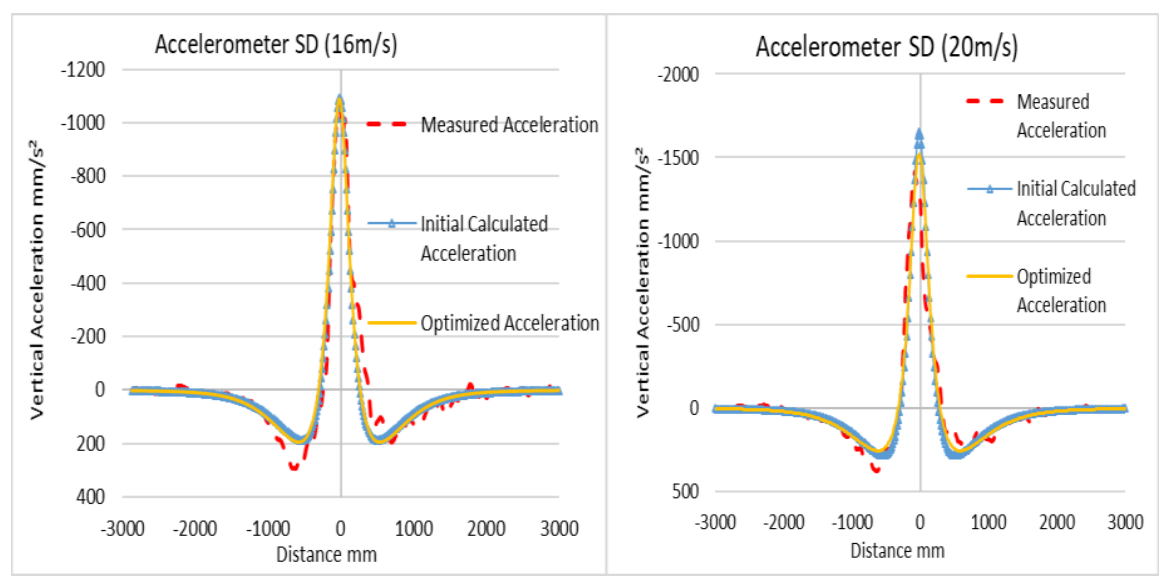

Fig. 5 Signal comparison between measured, calculated and best match responses with respect to two speeds

The calculated final differences between the modelling results and the measurements (error indicator R) are summarized in table 3.

Table 3 Relative Differences between the measured and calculated responses

\begin{tabular}{lcccc}
\hline & $\begin{array}{c}\text { Anchor Deflec- } \\
\text { tometer }\end{array}$ & $\begin{array}{c}\text { Geophone } \\
\text { Ion }\end{array}$ & $\begin{array}{c}\text { Accelerometer } \\
\text { CX }\end{array}$ & $\begin{array}{c}\text { Accelerometer } \\
\text { SD }\end{array}$ \\
\hline Difference 16m/s & $0.144 \mathrm{~mm}$ & $0.693 \mathrm{~mm} / \mathrm{s}$ & $29.81 \mathrm{~mm} / \mathrm{s}^{2}$ & $29.513 \mathrm{~mm} / \mathrm{s}^{2}$ \\
Percentage \% & $2.7 \%$ & $9.5 \%$ & $3.1 \%$ & $2.78 \%$ \\
Difference 20m/s & $0.009 \mathrm{~mm}$ & $0.758 \mathrm{~mm} / \mathrm{s}$ & $32.693 \mathrm{~mm} / \mathrm{s}^{2}$ & $33.53 \mathrm{~mm} / \mathrm{s}^{2}$ \\
Percentage \% & $1.9 \%$ & $8.4 \%$ & $2.6 \%$ & $2.36 \%$ \\
\hline
\end{tabular}

The average modulus values obtained after the optimization are given in tables 4 and 5. The back-calculated moduli of the pavement layers are generally close to the reference values obtained from laboratory tests and FWD measurements. However, in some cases, the calculated modulus is equal to the limit defined in the optimization procedure, which indicates some difficulties to converge. This occurs in particular for the asphalt layer modulus, for accelerometer CX (for the two speeds), and also for the geophone and deflectometer, for the speed of $16 \mathrm{~m} / \mathrm{s}$. This seems to indicate that the asphalt layer modulus has a relatively low influence on the calculated solution, for this pavement structure.

It is planned to perform other tests, on different pavement structures, to further evaluate and improve this back calculation procedure. However, these first results 
are very encouraging, and indicate that instrumentation with accelerometers and geophones can be used to determine pavement layer properties.

Table 4 Modulus values obtained after the optimization compared to the reference, at the speed of $16 \mathrm{~m} / \mathrm{s}$

\begin{tabular}{lccccc}
\hline Pavement Layer & $\begin{array}{c}\text { Reference } \\
\text { (MPa) }\end{array}$ & $\begin{array}{c}\text { Deflectometer } \\
\text { (MPa) }\end{array}$ & $\begin{array}{c}\text { Geophone } \\
\text { Ion (MPa) }\end{array}$ & $\begin{array}{c}\text { Accelerometer } \\
\text { CX (MPa) }\end{array}$ & $\begin{array}{c}\text { Accelerometer } \\
\text { SD (MPa) }\end{array}$ \\
\hline Bituminous layer & 9038 & 8000 & 8000 & 12000 & 9967 \\
Granular base & 145 & 155 & 154 & 100 & 100 \\
Subgrade & 110 & 120 & 150 & 107 & 122 \\
\hline
\end{tabular}

Table 5 Modulus values obtained after the optimization compared to the reference, at the speed of $20 \mathrm{~m} / \mathrm{s}$

\begin{tabular}{lccccc}
\hline Pavement Layer & $\begin{array}{c}\text { Reference } \\
\text { (MPa) }\end{array}$ & $\begin{array}{c}\text { Deflectometer } \\
\text { (MPa) }\end{array}$ & $\begin{array}{c}\text { Geophone } \\
\text { Ion (MPa) }\end{array}$ & $\begin{array}{l}\text { Accelerometer Accelerometer } \\
\text { CX (Ma) }\end{array}$ & SD (MPa) \\
\hline Bituminous layer & 9441 & 9500 & 8569 & 12000 & 9998 \\
Granular base & 145 & 100 & 132 & 175 & 100 \\
Subgrade & 110 & 137 & 150 & 67 & 101 \\
\hline
\end{tabular}

\section{Conclusion}

The overall approach of this work is to use embeddable sensors in the asphalt layer to measure the pavement response (vertical displacement, velocity and acceleration). For this purpose, an experimental pavement was tested on the IFSTTAR APT facility, instrumented with an anchored deflectometer, a geophone and 2 types of accelerometers, and submitted to $65 \mathrm{KN}$ dual wheel loads, and different loading speeds. The data collected for speeds of $20 \mathrm{~m} / \mathrm{s}$ and $16 \mathrm{~m} / \mathrm{s}$ is considered in this work. The measured responses have been compared with calculations performed with a layer-elastic model, and a procedure for back calculation of pavement layer moduli has been proposed. The first results show a good match between the modelled and measured responses, and realistic back-calculated moduli. An error indicator $\mathrm{R}$ has been used to estimate the relative difference between the responses. The deflectometer gives the best match among the different sensors, however this type of sensor is not very suitable for real road monitoring, due to its high cost and difficulty of installation. The results obtained with the two accelerometers are very similar, with maximum relative differences of $2.78 \%$ and 3.1 $\%$ respectively. The geophone gives slightly less accurate results. 
Following the APT test, it is planned to install the sensors on a real road section, to perform measurements under real heavy vehicle traffic, and also to improve the modelling approach, by taking into account a visco-elastic model for the asphalt materials.

\section{Acknowledgements}

"The research presented in this paper was carried out as part of the H2020-MSCA-ETN-2016. This project has received funding from the European Union's H2020 Program for research, technological development and demonstration under grant agreement number 721493"

\section{References}

Arraigada M et al. (2009) Evaluation of accelerometers to determine pavement deflection under traffic loads. journal materials and structures 42: 779-790.

Bahrani et al, (2019) The study of geophones and accelerometers for pavement instrumentation and assessment. International Conference on Smart infrastructure and Construction, University of Cambridge, 8-10 July 2019.

Clark R et al (1991), Calculating pavement deflections with velocity transducers, Proceedings. Transportation Research record 1293,TRB.

Duong N.S et al (2018), Monitoring of pavements using the geophones, International journal of pavements Engineering. DOI 10.1080/10298436.2018.1432859

Fylstra D et al (1998), Design and use of the Microsoft Excel Solver. Interfaces, 28(5):29-55.

Lajnef N. et al. (2013) Smart pavement monitoring system. Report FHWA-HRT-12-072, TurnerFairbank Highway Research Center, McLean, VA.

Levenberg E et al (2014), Wireless pavement sensors for wide-area instrumentation, Proceedings of the 3rd International Conference on Transportation Infrastructure (ICTI), pp. 307-319, CRC Press, Taylor and Francis Group.

Levenberg E et al. (2009) Validation of NCAT Structural Test Track Experiment using INDOT APT Facility. Final Report, Joint Transportation Research Program, Report FHWA/IN/JTRP2008/26, Purdue University, 2009.

Levenberg E. (2015) Backcalculation with an implanted inertial sensor, Transportation Research Record: Journal of the Transportation Research Board, 2525:3-12.

Levenberg, E. (2012) Inferring pavement properties using an embedded accelerometer. International Journal of Transportation Science and Technology, 3: 229-246.

Liu, P. et al (2017) Measurement and evaluation on deterioration of asphalt pavements by geophones. Measurement, 109: 223-232.

Nazarian S et al (1989) Determination of deflection of pavement systems using velocity transducers. Transportation Research Record 1227,TRB 147-158.

T Ryynänen et al (2010) The use of accelerometers in the pavement performance monitoring and analysis. IOP Conf. Ser.: Mater. Sci. Eng. 2010.

Tholen O et al (1985) Comparison of FWD with other deflection testing devices. Transportation research record 1007, TRB. Washington, DC: National Research Council: 20-26. 